\title{
Erratum
}

Christoph Riedweg*

\section{Konrad F. Zawadzki: Der Kommentar Cyrills von Alexandrien zum 1. Korintherbrief. Einleitung, kritischer Text, Übersetzung, Einzelanalyse}

DOI 10.1515/zac-2016-9001

Erratum to: Riedweg, Christoph: Konrad F. Zawadzki: Der Kommentar Cyrills von Alexandrien zum 1. Korinterbrief. Einleitung, kritischer Text, Übersetzung, Einzelanalyse, Traditio Exegetica Graeca 16, Leuven (Peeters) 2015, XXVIII + 615 S., ISBN 978-90-429-3045-2, € 105,-. Zeitschrift für Antikes Christentum. Band 20. heft 1. Seite 187-192. (DOI 10.15.15/zac-2015-9001):

Die DOI wurde doppelt vergeben und deshalb geändert von DOI: 10.15.15/zac2015-0016 zu 10.15.15/zac-2015-9001.

*Kontakt: Christoph Riedweg, Universität Zürich, E-Mail: christoph.riedweg@uzh.ch 